\title{
Paraneoplastic acral vascular syndrome
}

\author{
Philipp Jud MD, Reinhard B. Raggam MD, Franz Hafner MD \\ Cite as: CMAJ 2020 November 16;192:E1470. doi: 10.1503/cmaj.200430
}

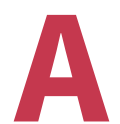

n 85-year-old man with a history of recurrent non-small cell lung adenocarcinoma presented to the clinic with a 2-week history of painful cyanosis and necrosis of his fingers (Figure 1), along with weight loss, dry cough and dyspnea. He had been diagnosed 5 years earlier with Raynaud phenomenon (not strictly linked to cold exposure), and over the past 2 years he had developed recurrent digital tip ulcers. He had undergone a lobectomy 10 years earlier for the lung cancer, but was diagnosed with a recurrence 2 months before this presentation.

On physical examination, the patient had acral cyanosis and necrosis; his ulnar pulses were bilaterally undetectable by palpation. He had no other signs of connective tissue disease or vasculitis. The results of laboratory testing were unremarkable (including a complete blood count, erythrocyte sedimentation rate, coagulation parameters, urinalysis, antibodies against hepatitis B and C, cryoglobulins and several autoantibodies), other than elevation of the C-reactive protein level $(99.1 \mathrm{mg} / \mathrm{L}$ [reference range 0-5 mg/L]). Colour-coded duplex sonography showed occluded ulnar and palmar arteries bilaterally; nailfold capillaroscopy was unremarkable. We diagnosed paraneoplastic acral vascular syndrome, and treated the patient palliatively with intravenous iloprost $20 \mu \mathrm{g}$ for 10 days and oral hydromorphone $1.3 \mathrm{mg}$ as needed. The acral necrosis progressed to his feet 2 weeks after presentation, and he died a month later (Appendix 1 , available at www.cmaj.ca/lookup/doi/10.1503/cmaj.200430/ tab-related-content).

Paraneoplastic acral vascular syndrome is a rare vascular disease. In $50 \%$ of cases, it is associated with adenocarcinoma without male or female predominance. ${ }^{1,2}$ It presents with manifestations of digital ischemia, including Raynaud phenomenon, acrocyanosis and digital gangrene. ${ }^{1,3}$ According to a retrospective review of 15 cases, the median time between cancer diagnosis and acral necrosis is 2 months (range 1-9 months). ${ }^{2}$ Digital gangrene seems to occur concomitantly with or after cancer

Competing interests: None declared.

This article has been peer reviewed.

The authors have obtained patient consent.

Affiliation: Division of Angiology, Department of Internal Medicine, Medical University of Graz, Graz, Austria

Acknowledgement: The authors thank Holger Flick MD for his contributions to this article.

Correspondence to: Philipp Jud, philipp.jud@medunigraz.at
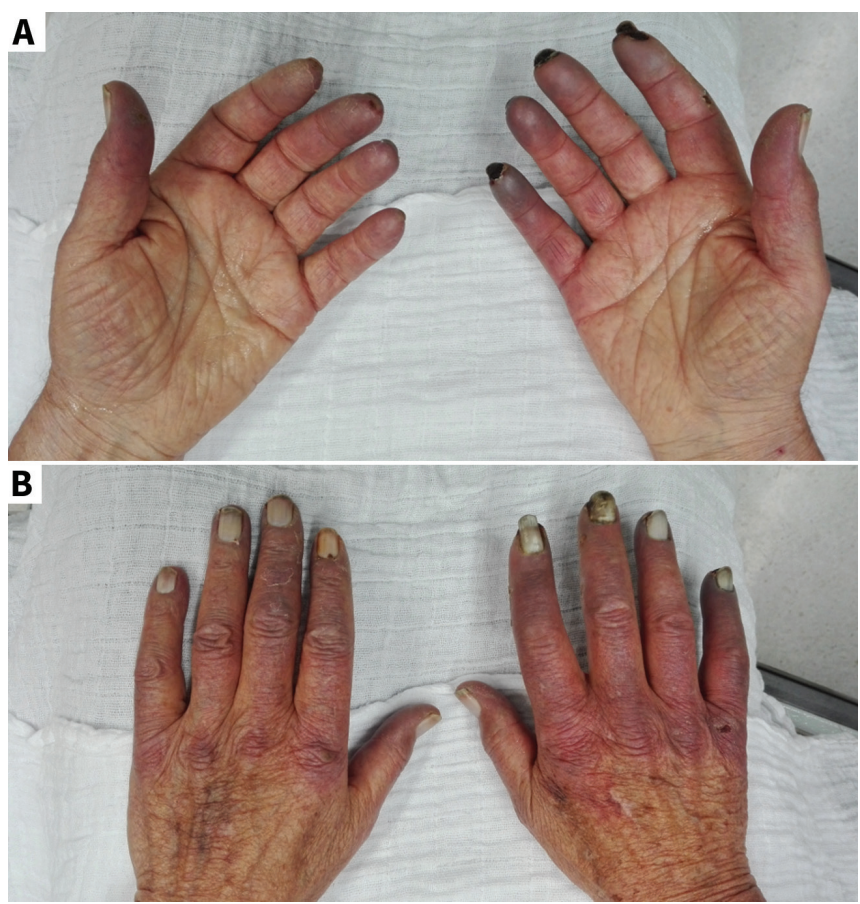

Figure 1: (A) Cyanosis of an 85-year-old man's finger tips, with necrosis of the right second to fifth fingers, as well as of the left thumb, index and middle fingers. (B) Livid skin discoloration of the second to fifth dorsal fingers and dorsal metacarpophalangeal joints.

diagnosis; however, it may also precede the cancer diagnosis. Several mechanisms have been proposed, including tumour invasion of the sympathetic nervous system, microembolism of tumour fragments, blood hyperviscosity and an overproduction of vasoconstrictive, thrombogenic and immunological mediators by tumour cells. ${ }^{1,4,5}$ Most cases resolve when the underlying tumour can be treated; prostaglandins may offer relief. ${ }^{2}$

\section{References}

1. Poszepczynska-Guigné E, Viguier M, Chosidow O, et al. Paraneoplastic acral vascular syndrome: epidemiologic features, clinical manifestations, and disease sequelae. J Am Acad Dermatol 2002;47:47-52.

2. Le Besnerais M, Miranda S, Cailleux N, et al. Digital ischemia associated with cancer: results from a cohort study. Medicine (Baltimore) 2014;93:e47.

3. Chow SF, McKenna $\mathrm{CH}$. Ovarian cancer and gangrene of the digits: case report and review of the literature. Mayo Clin Proc 1996;71:253-8.

4. Hsu ST, Lee YY, Lie MF. Symmetrical peripheral gangrene of sudden onset - a paraneoplastic syndrome? - a case report and review of the literature. Dematol Sinica 1996;14:82-8.

5. Falanga A, Marchetti M, Vignoli A. Coagulation and cancer: biological and clinical aspects. J Thromb Haemost 2013;11:223-33. 